Jurnal Media Agribisnis Vol. 4 No. 1 Tahun 2019 Hal 34 - 42

Media Komunikasi Hasil Penelitian Bidang Ilmu Agribisnis

ISSN print 2548-7027

ISSN online 2541-6898

\title{
KONDISI EKONOMI AGROINDUSTRI KERIPIK SINGKONG (Manihot Utilissima) MBAK SUR \\ DI DESA MEKARSARI KECAMATAN KUMPEH KABUPATEN MUARO JAMBI
}

\author{
${ }^{1)}$ Rogayah dan ${ }^{2)}$ Eko Haryanto \\ ${ }^{1)}$ Program Studi Agribisnis, Fakultas Pertanian Universitas Batanghari \\ ${ }^{2)}$ Alumni Program Studi Agribisnis, Fakultas Pertanian Universitas Batanghari \\ Jl. Slamet Riyadi-Broni, Jambi. 36122. Telp. +6274160103 \\ ${ }^{1)}$ Email korespondensi : rogayah.gayah1959@gmail.com
}

\begin{abstract}
In order to help entrepreneurs to know the business being run was profitable or not and the amount of added value obtained, a study was conducted on the business concerned in Ms. Sur's cassava crispy Agroindustry at Mekarsari Village, Kumpeh District, Muaro Jambi Regeney. This research has the aims to find out the deskription of this Agroindustry activities and also to kno the economic aspect involved : income, break event point and payback period. Deskription analysis was applied in this study, completed by purposive random sampling method to get this Ms, Sur's Agroindustry as a sample.

The result of this research showed that this agroindustry had high enough income as Rp. 8.451,560/month, with production break event point as 9,245 packs/month and price break event point as Rp. 370/pack. While the payback period showed 0,75 month. And the value added per kilogram cassava was Rp. 37.371.
\end{abstract}

Keyword : income, agroindustry, cassava

\begin{abstract}
Abstrak
Guna membantu pengusaha mengetahui usaha yang dijalankan menguntungkan atau tidak dan besarnya nilai tambah yang diperoleh maka dilakukan suatu penelitian pada usaha yang bersangkutan yaitu Agroindustri keripik singkong Mbak Sur di Desa Mekarsari Kecamatan Kumpeh Kabupaten Muaro Jambi. Tujuan untuk melihat gambaran aktivitas agroindustri, untuk mengetahui aspek ekonomi yaitu : pendapatan, titik impas (BEP) dan titik balik modal (payback period). Menggunakan analisis deskriptif dengan teknik pengambilan sampel secara sengaja yaitu pada Agroindustri Mbak Sur. Hasil penelitian menunjukan bahwa agroindustri ini memiliki pendapatan sebesar Rp. 8.451, 560/bulan. Dengan break event point produksi 9.245 bungkus/bulan dan break event point harga Rp 370/bungkus. Sedangkan titik balik modal terjadi pada waktu mencapai 0,75 bulan dan nilai tambah perkilogram singkong adalah Rp. 37.371.
\end{abstract}

Kata kunci : Pendapatan, agroindustri, singkong

\section{PENDAHULUAN}

Sektor pertanian merupakan sektor prioritas utama yang mendapat perhatian oleh berbagai kalangan ekonomi di Indonesia. Hal ini dikarenakan, pertanian merupakan sektor yang dominan dalam ekonomi nasional, memberikan

Diterbitkan oleh Program Studi Agribisnis Fakultas Pertanian Universitas Batanghari Jambi Halaman 34 
Jurnal Media Agribisnis Vol. 4 No. 1 Tahun 2019 Hal 34 - 42

Media Komunikasi Hasil Penelitian Bidang Ilmu Agribisnis

ISSN print 2548-7027

ISSN online 2541-6898

kontribusi bagi pendapatan nasional, membuka kesempatan kerja bagi penduduk yang jumlahnya semakin bertambah dan kontribusinya terhadap devisa negara.

Pengembangan agroindustri merupakan salah satu strategi pembangunan pertanian. Salah satu jenis agroindustri makanan adalah agroindustri yang mengolah komoditi umbi-umbian, seperti singkong (Manihot Utilissima) merupakan umbi yang memiliki banyak keistimewaan selain rasanya yang enak dengan kandungan karbohidrat yang cukup tinggi, mempunyai komposisi gizi yang cukup tinggi dan nilai jual yang tinggi juga (Mubyarto, 1995).

Agroindustri keripik singkong di Kecamatan Kumpeh pada saat ini masih dikelola dalam skala industri kecil menengah dengan jumlah tenaga kerja yang relatif sedikit. Dengan demikian agroindustri keripik singkong masih memungkinkan untuk dikembangkan dimasa yang akan datang, mengingat industri pengolahan singkong di Kabupaten Muaro Jambi khususnya di Kecamatan Kumpeh masih cukup terbatas hal ini memungkinkan peluang pasar yang cukup luas. Hal ini terlihat dari beberapa industry makanan yang ada di Kecamatan Kumpeh yaitu: Industri Bakso 6 Unit, Mie Ayam 8 Unit,Soto 2 Unit, Tempe 2 Unit, Tahu 1 Unit, Peyek 3 Unit,Keripik Singkong 1 Unit, Keripik pisang 2 Unit. Dinas Perindustrian, Perdagangan dan Koperasi Kabupaten Muaro Jambi, 2015

Dari delapan (8) unit industri yang ada di Kecamatan Kumpeh, dan satu unit industri yang mengolah komoditi singkong menjadi keripik singkong yaitu agroindustri keripik singkong Mbak Sur.

Aspek ekonomi keripik singkong berperan dalam meningkatkan pendapatan, mensejahterakan pelaku usaha,dan menyerap tenaga kerja. Relatif tingginya permintaan keripik singkong hal ini terlihat dari setiap kali dipasarkan selalu tidak tersisa bahkan pada periode memasarkan berikutnya volume produksi ditingkatkan juga akan terserap oleh pasar, kondisi ini merupakan gambaran bagi usaha untuk meningkatkan produksi keripik singkongnya.

Berdasarkan uraian latar belakang maka penulis tertarik membuat tulisan dengan judul Kondisi Ekonomi agroindustri Keripik Singkong (Manihot Utilissima) Mbak Sur Di Desa Mekarsari Kecamatan Kumpeh Kabupaten Muaro Jambi. Dengan merumuskan masalah sebagai berikut:

1. Bagaimana gambaran usaha keripik singkong Mbak Sur?

2. Bagaimana kondisi aspek ekonomi (pendapatan, Break Event Point, Payback Periode, Nilai Tambah) usaha keripik singkong Mbak Sur ?

Adapun tujuan dari penelitian ini untuk :

1. Mendeskripsikan usaha keripik singkong Mbak Sur.

2. Menganalisis aspek ekonomi (pendapatan, Break Event Point, Payback Periode, Nilai Tambah) usaha keripik singkong Mbak Sur.

\section{METODOLOGI PENELITIAN}

Penelitian ini dilakukan pada usaha Agroindustri keripik singkong Mbak Sur yang berada di Desa Mekarsari Kecamatan Kumpeh Kabupaten Muaro Jambi. Penentuan lokasi penelitian secara purposive (sengaja) dengan pertimbangan bahwa di Desa Mekarsari hanya ada satu industri yang mengelola singkong menjadi keripik singkong yang telah berdiri selama lima tahun.

Diterbitkan oleh Program Studi Agribisnis Fakultas Pertanian Universitas Batanghari Jambi Halaman 35 
Jurnal Media Agribisnis Vol. 4 No. 1 Tahun 2019 Hal 34 - 42

Media Komunikasi Hasil Penelitian Bidang Ilmu Agribisnis

ISSN print 2548-7027

ISSN online 2541-6898

Data yang digunakan bersumber dari data primer dan data sekunder. Data primer merupakan data yang diperoleh dan dikumpulkan langsung dari pengusaha agroindustri keripik singkong di daerah penelitian. Data sekunder adalah data yang diperoleh dari hasil publikasi, instansi terkait, laporan-laporan dan literatur pustaka yang ada relefansinya dengan penelitian ini. Jenis data yang digunakan time series atau runtun waktu yang diambil dalam rentan waktu 1 tahun.

Metode analisis data yang digunakan adalah analisis deskriptif baik untuk data kualitatif maupun kuantitatif. Analisis pendapatan digunakan rumus (Soekartawi, 1995). Secara matematis pendapatan usahatani diformulasikan sebagai berikut :

$$
\mathrm{Pd}=\mathrm{TR}-\mathrm{TC} \ldots \ldots \ldots \ldots . . . . . \mathrm{TC}=\mathrm{FC}+\mathrm{VC}
$$

Dimana :

$\mathrm{Pd} \quad=$ Pendapatan usaha keripik $(\mathrm{Rp} / \mathrm{bln})$

$\mathrm{TR}=$ Total Revenue atau Total Penerimaan $(\mathrm{Rp} / \mathrm{bln})$

Dimana TR $=$ Jumlah produksi X Harga

TC = Total Cost atau Total biaya (Rp/bln)

$\mathrm{FC} \quad=$ Fixed Cost atau Biaya Tetap $(\mathrm{Rp} / \mathrm{bln})$

$\mathrm{VC}=$ Variabel Cost atau Biaya Variabel (Rp/bln)

Untuk menghitung besarnya biaya tetap, dihitung berdasarkan nilai penyusutan alat yang digunakan, menggunakan rumus sebagai berikut : (Syafri,2002):

$$
\mathrm{D}=\frac{\mathrm{P}-\mathrm{S}}{\mathrm{N}}
$$

Keterangan :

$$
\begin{aligned}
& \mathrm{D}=\text { Biaya Penyusutan (Rp/bulan) } \\
& \mathrm{P}=\text { Harga awal alat (Rp) } \\
& \mathrm{S}=\text { Harga ahir alat (Rp) dengan asumsi sama dengan nol } \\
& \mathrm{N}=\text { Perkiraan umur ekonomis (Bulan) }
\end{aligned}
$$

Analisis Break Even Point menggunakan rumus (Sarwono, 2007),sebagai berikut:

$$
\text { BEP Produksi }=\frac{\text { Total Biaya }}{\text { Harga Jual }} \text { dan } \quad \text { BEP Harga }=\frac{\text { Total Biaya }}{\text { Produksi }}
$$

Analisis payback period digunakan rumus (Bambang Riyanto, 2011), sebagai berikut :

$$
\mathrm{PP}=\frac{\text { Investasi }}{\text { NetBenefit }} \times 1 \text { Tahun }
$$

Dimana :

$\mathrm{PP} \quad=$ Payback Period $(\mathrm{Bln})$

Investasi $\quad=$ Modal yang ditanamkan dalam usaha $(\mathrm{Rp})$

Net benefit $=$ Laba bersih setelah pajak dalam usaha $(\mathrm{Rp} / \mathrm{Bln})$

Untuk melihat berapa besar nilai tambah dari proses pengolahan singkong menjadi keripik singkong digunakan rumus Hayami (1987) sebagai berikut:

Diterbitkan oleh Program Studi Agribisnis Fakultas Pertanian Universitas Batanghari Jambi Halaman 36 
Jurnal Media Agribisnis Vol. 4 No. 1 Tahun 2019 Hal 34 - 42

Media Komunikasi Hasil Penelitian Bidang Ilmu Agribisnis

ISSN print 2548-7027

ISSN online 2541-6898

$$
\mathrm{NT}=\mathrm{NP}-(\mathrm{NBB}+\mathrm{NBP})
$$

Keterangan :

NT = Nilai Tambah $(\mathrm{Rp} / \mathrm{Kg})$

$\mathrm{NP} \quad=$ Nilai Produk Olahan $(\mathrm{Rp} / \mathrm{Kg})$

$\mathrm{NBB}=$ Nilai Bahan Baku $(\mathrm{Rp} / \mathrm{Kg})$

$\mathrm{NBP}=$ Nilai Bahan Penunjang $(\mathrm{Rp} / \mathrm{Kg})$

\section{Identitas Responden}

\section{HASIL DAN PEMBAHASAN}

Responden yaitu orang yang menjadi sumber informasi dalam melengkapi data yang dibutuhkan. Ditempat penelitian terdapat 4 orang responden yaitu diantaranya 1 orang pemilik usaha dan 3 lainnya merupakan karyawan. Dari keempat responden tersebut rata-rata berumur 39,5 tahun dengan umur tertinggi yaitu Mbak Sur dengan umur 45 tahun dan usia paling rendah yaitu Ibu Tuminah dengan umur 35 tahun,pendidikan terakhir responden yaitu 2 orang tamatan SD dan 2 orang lagi tamatan SMP, lama bekerja, ditempat usaha Mbak Sur bervariasi. Mbak Sur bekerja selama 6 tahun, kemudian 2 orang telah bekerja selama 3 tahun dan 1 orang sudah bekerja selama 5 tahun.

\section{Gambaran Usaha Agroindustri Keripik Singkong Mbak Sur}

Agroindustri Keripik Singkong Mbak Sur adalah sebuah usaha kecil menengah yang berada di Desa Mekarsari Kecamatan Kumpeh Kabupaten Muaro Jambi didirikan pada tahun 2011 dengan menggunakan modal sendiri sebesar Rp 1.000.000,-,yang dikerjakan

oleh ibu Suryani dan keluarganya, dan dalam proses promosi ibu Suryani mendatangi setiap warung yang ada di Kecamatan Kumpeh dan menawarkan produknya untuk dititipkan di warung tersebut. Dengan semakin banyaknya permintaan dan semakin berkembangnya usaha dari ibu Suryani tersebut maka Ibu suryani mempekerjakan lagi 3 karyawan dari lingkungan sekitar untuk membantu proses produksinya dengan gaji Rp 120.000,-/hari dengan jam kerja masuk jam 08.00-12.00, istirahat jam 12.00-13.30, kemudian masuk lagi jam 13.30-17.00, istirahat jam 17.00-19.00 kemudian dilanjut lagi kerja jam 19.00-21.00. Rata-rata ibu Suryani memproduksi $100 \mathrm{~kg}$ keripik singkong per minggu atau terdapat 5000 bungkus dengan berat perbungkus sebesar 20 gram dan untuk menghasilkan keripik sebanyak itu membutuhkan bahan baku singkong sebesar $400 \mathrm{~kg}$ dan bahan baku tersebut didapat dari pengepul yang ada di Kecamatan Kumpeh dan bahan baku tersebut diantar langsung oleh pengepul ke tempat ibu Suryani. Kegiatan produksi dilakukan dengan hari kerja sebanyak 2 hari kerja dalam satu minggu, dan untuk 1 bulannya terdapat 8 hari kerja. Sedangkan untuk mengantar keripik ke warung-warung penitipan dilakukan oleh suami ibu Suryani sendiri sehingga tidak mengeluarkan biaya upah tenga kerja.

Proses produksi keripik singkong pada Agroindustri Mbak Sur dimulai dari pengupasan singkong, pencucian, pengirisan, penggorengan, penirisan, pengadukan bumbu sampai pada pengemasan keripik singkong. Pengupasan kulit singkong dilakukan dengan menggunakan pisau sampai kulit luar dari singkong tersebut bersih, setelah dilakukan pengupasan singkong dicuci dan ditiriskan. Setelah singkong ditiriskan dan sudah kering maka dilakukan pengirisan dengan

Diterbitkan oleh Program Studi Agribisnis Fakultas Pertanian Universitas Batanghari Jambi Halaman 37 
Jurnal Media Agribisnis Vol. 4 No. 1 Tahun 2019 Hal 34 - 42

Media Komunikasi Hasil Penelitian Bidang Ilmu Agribisnis

ISSN print 2548-7027

ISSN online 2541-6898

menggunakan mesin pengiris atau mesin slicer. Setelah dilakukan pengirisan kemudian singkong yang telah diiris digoreng sampai kekeringan yang sudah ditentukan, setelah digoreng lalu ditiriskan di saringan kawat. Keripik yang sudah ditiriskan dicampurkan dengan bumbu yang telah disiapkan sebelumnya. Setelah keripik diaduk rata dengan bumbu maka dilakukan pengemasan ke dalam plastik. Plastik terlebih dahulu disiapkan dan dimasukkan label, kemudian keripik dimasukkan dengan berat 20 gram per bungkus. Setelah keripik dimasukkan ke dalam plastik dipress dengan mesin sealer agar plastik kemasan tertutup dengan rapat dan tidak masuk angin.

Untuk proses pemasaran keripik Mbak Sur ini suami ibu Suryani mengantar keripik dengan menggunkan motor untuk dititipkan diwarung, dengan sistem seperti itu ibu Suryani menitip di warung-warung tersebut dengan perhitungan 8 : 2 artinya dengan harga keripik Rp 1.000,- ibu Suryani menerima sebesar Rp 800,dan pemilik warung akan menerima sebesar Rp 200,-. dengan sistem seperti itu pemilik warung akan membayar jika keripiknya sudah terjual sedangkan yang belum laku belum dibayarkan dan jika keripik ada yang tidak laku dan sudah tidak layak lagi kondisinya maka keripik tersebut akan dibawa kembali oleh ibu Suryani.

Untuk kendala yang dihadapi oleh Agroindustri Mbak Sur ini adalah pada waktu kondisi banjir tahunan akan mempengaruhi ketersediaan bahan baku singkong yang dibutuhkan. Sehingga untuk mengatasinya harus dipesan dari jauhjauh hari agar pedagang pengepul bisa menyediakan bahan baku ubi tersebut. Untuk lebih jelasnya rata-rata investasi pada agroindustri keripik singkong Mbak Sur dapat dilihat pada Tabel 2:

Tabel 2. Rat-Rata Investasi Agroindustri Keripik Singkong Mbak Sur Tahun 2016-2017

\begin{tabular}{rlrrr}
\hline No & \multicolumn{1}{c}{ Nama } & $\begin{array}{c}\text { Jumlah } \\
\text { (Unit) }\end{array}$ & $\begin{array}{c}\text { Harga } \\
\text { satuan } \\
\text { (Rp/unit) }\end{array}$ & \multicolumn{2}{c}{ Total (Rp) } \\
\hline 1 & Mesin Slicer & 1 & 4.500 .000 & 4.500 .000 \\
2 & Mesin Sealer & 1 & 500.000 & 500.000 \\
3 & Kompor Gas & 2 & 200000 & 400000 \\
4 & Kuali & 2 & 200000 & 40000 \\
5 & Sendok Goreng & 2 & 15000 & 30000 \\
6 & Saringan kecil & 2 & 12000 & 24000 \\
7 & Saringan Besar & 2 & 20000 & 40000 \\
8 & Ember & 4 & 30000 & 120000 \\
9 & Pisau & 4 & 20000 & 80000 \\
10 & Gunting & 2 & 25000 & 50000 \\
11 & Blender & 1 & 350000 & 350000 \\
12 & Timbangan & 1 & 200000 & 200000 \\
13 & Keranjang & 1 & 50000 & 50000 \\
\hline & Jumlah & & & 6.384 .000 \\
\hline
\end{tabular}

Sumber : Data Primer Diolah Tahun 2017

Diterbitkan oleh Program Studi Agribisnis Fakultas Pertanian Universitas Batanghari Jambi Halaman 38 
Jurnal Media Agribisnis Vol. 4 No. 1 Tahun 2019 Hal 34 - 42

Media Komunikasi Hasil Penelitian Bidang Ilmu Agribisnis

ISSN print 2548-7027

ISSN online 2541-6898

Berdasarkan Tabel 2 diatas menunjukkan bahwa biaya investasi untuk agroindustri keripik singkong Mbak Sur adalah sebesar Rp 6.384.00,- dan untuk biaya investasi terbesar adalah digunakan untuk biaya investasi mesin slicer yaitu sebesar Rp. 4.500.000,-.

Biaya Produksi Agroindustri Keripik Singkong Mbak Sur Tahun 20162017 Biaya produksi pada agroindustri keripik singkong Mbak Sur adalah jumlah dari total biaya tetap (fixed cost)dan biaya tidak tetap (variable cost). Biaya tetap adalah biaya yang harus dikeluarkan dalam proses produksi dan tidak habis dalam satu kali proses produksi. Biaya tidak tetap adalah biaya yang digunakan dalam proses produksi dan habis satu kali proses produksi. Pada agroindustri keripik singkong Mbak Sur, biaya tetap disini adalah biaya penyusutan alat yang dihitung berdasarkan nilai ekonomis alatalat yang digunakan yang terdiri dari mesin slicer, mesin sealer, kompor gas, kuali, sendok goreng, saringan besar, saringan kecil, ember, pisau, gunting, blender, timbangan dan keranjang. Sedangkan untuk biaya tidak tetap terdiri dari biaya pembelian singkong, minyak goreng, gas, plastik kemasan, cabai, garam, kertas label, bumbu, bensin, bibit, serta biaya penggunaan tenaga kerja termasuk ke dalam biaya tidak tetap yang harus dikeluarkan dalam kegiatan usaha.

Rata-rata jumlah komponen biaya-biaya dalam agroindustri keripik singkong Mbak Sur.

Tabel 3. Jumlah Rata-Rata Biaya Pada Agroindustri Keripik Singkong Mbak Sur Tahun 2016-2017

\begin{tabular}{llr}
\hline No $\quad$ Uraian Komponen Biaya & Jumlah Biaya $(\mathrm{Rp} / \mathrm{B} \ln )$ & $\begin{array}{r}\text { Persentase } \\
(\mathbf{\%})\end{array}$ \\
\hline $1 \quad$ Biaya Tetap & & 0,99 \\
Mesin Slicer & 75000 & 0,18 \\
Mesin Sealer & 13889 & 0,15 \\
Kompor Gas & 11111 & 0,01 \\
Kuali & 833 & 0,01 \\
Sendok Goreng & 833 & 0,01 \\
Saringan Kecil & 1000 & 0,02 \\
Saringan Besar & 1667 & 0,13 \\
Ember & 10000 & 0,03 \\
Pisau & 2222 & 0,03 \\
Gunting & 2083 & 0,39 \\
Blender & 29167 & 0,11 \\
Timbangan & 8333 & 0,06 \\
Keranjang & 4167 & $\mathbf{2 , 1 2}$ \\
Jumlah & $\mathbf{1 6 0 3 0 6}$ & \\
Biaya Tidak Tetap & & 39,75 \\
Singkong & 3000000 & 9,87 \\
Minyak Goreng & 745000 & 2,07
\end{tabular}

Diterbitkan oleh Program Studi Agribisnis Fakultas Pertanian Universitas Batanghari Jambi Halaman 39 
Jurnal Media Agribisnis Vol. 4 No. 1 Tahun 2019 Hal 34 - 42

Media Komunikasi Hasil Penelitian Bidang Ilmu Agribisnis

ISSN print 2548-7027

ISSN online 2541-6898

\begin{tabular}{lrr}
\hline \hline Plastik Kemasan & 56333 & 0,75 \\
Cabai & 434000 & 5,75 \\
Garam & 4000 & 0,05 \\
Kertas Label & 20000 & 0,26 \\
Bumbu & 13667 & 0,18 \\
Bensin & 78600 & 1,04 \\
Upah Tenaga Kerja & 2880000 & 38,16 \\
\hline Jumlah & $\mathbf{7 3 8 7 6 0 0}$ & $\mathbf{9 7 , 8 8}$ \\
\hline Jumlah (1+2) & $\mathbf{7 5 4 7 9 0 6}$ & $\mathbf{1 0 0}$ \\
\hline
\end{tabular}

Sumber: Data Primer Diolah Tahun 2017

Berdasarkan Tabel 3 di atas dapat dilihat bahwa dari total biaya sebesar Rp. 7.547.906,- terdiri dari biaya tetap sebesar Rp. 160.306,- dimana komponen terbesar biaya tetap terdapat pada biaya mesin slicer yaitu sebesar Rp. 75.000,-, dengan persentase sebesar $0,99 \%$. Kemudian biaya tidak tetap sebesar Rp. 7.387.600,-, dimana komponen terbesar biaya tidak tetap terdapat pada biaya bahan baku singkong sebesar Rp. 3.000.000,- dengan persentase sebesar 39,75\%.

\section{Penerimaan Agroindustri Keripik Singkong Mbak Sur}

Penerimaan agroindustri akan sangat tergantung pada volume produksi dan harga jual. Jika volume produksi dan harga jual tinggi maka penerimaan juga akan naik. Penerimaan Agroindustri ini di dapat dari jumlah produksi dikali dengan harga produk.

Tabel 4. Rata-Rata Jumlah Produksi, Harga, Penerimaan Pada Agroindustri Keripik Singkong Mbak Sur Tahun 2016-2017

Berdasarkan Tabel 4 diatas terlihat bahwa jumlah produksi yang dihasilkan rata-rata per bulan adalah sebesar 19999,33 bungkus per bulan dengan harga Rp. 800,- dengan jumlah penerimaan sebesar Rp. 15.999.467,- per bulan.

Pendapatan usaha adalah selisih antara total penerimaan dengan total biaya yang dikeluarkan untuk menghasilkan keripik singkong.

Tabel 5. Rata-Rata Penerimaan, Total Biaya, dan Pendapatan Pada Agroindustri Keripik Singkong Mbak Sur Tahun 2016-1017

\begin{tabular}{llc}
\hline No & Uraian & Jumlah $(\mathrm{Rp} / \mathrm{B} \ln )$ \\
\hline 1 & Penerimaan & 15.999 .467 \\
2 & Total Biaya & 7.547 .906 \\
3 & Pendapatan & 8.451 .560 \\
\hline
\end{tabular}

Sumber: Data Primer Diolah Tahun 2017

Diterbitkan oleh Program Studi Agribisnis Fakultas Pertanian Universitas Batanghari Jambi Halaman 40 
Jurnal Media Agribisnis Vol. 4 No. 1 Tahun 2019 Hal 34 - 42

Media Komunikasi Hasil Penelitian Bidang Ilmu Agribisnis

ISSN print 2548-7027

ISSN online 2541-6898

Berdasarkan Tabel 5 diatas dapat dilihat bahwa agroindustri keripik ini memeperoleh perimaan sebesar Rp 15.999.467,- per bulan. Sedangkan untuk total biaya produksi sebesar Rp 7.547.906,- per bulan. Dari jumlah tersebut dapat dilihat bahwa penerimaan lebih besar dari total biaya sehingga agroindustri ratarata memperoleh pendapatan sebesar $\mathrm{Rp} 8.451 .560$,- per bulan.

Break Event Point (BEP) merupakan suatu keadaan dimana hasil usaha yang diperoleh sama dengan modal yang dikeluarkan sehingga tidak untung dan tidak rugi. BEP terdiri dari BEP produksi dan BEP harga. BEP produksi yaitu titik balik modal untuk jumlah produk yang diukur dalam satuan bungkus per bulan (Bungkus/Bln). Sedangkan BEP harga yaitu titik balik modal untuk harga jual produk per bungkus dalam satuan rupiah per bungkus (Rp/Bungkus). Dimana agroindustri keripik singkong Mbak Sur ini akan mencapai BEP produksi apabila telah menghasilkan 9.245. bungkus/bulan,dan akan mencapai BEP harga apabila harga produk minimal $\mathrm{Rp} 377$,-/bungkus. Berdasarkan perhitungan analisis yang didapat yaitu jumlah produksi sebanyak 9.245 bungkus/bulan dibandingkan dengan produksi pada agroindustri Mbak Sur yaitu sebanyak 19999 bungkus/bulan, dimana jumlah produksi lebih besar dari BEP produksi maka dapat dinyatakan usaha agroindustri keripik singkong Mbak Sur ini layak untuk diusahakan. Selanjutnya dilihat dari nilai BEP harga yaitu sebesar Rp 370,-/bungkus, jika dibandingkan dengan harga jual produk sebesar Rp 800,-/bungkus, maka BEP harga lebih kecil dibandingkan harga jual produk dengan demikian usaha agroindustri keripik singkong Mbak Sur ini layak untuk diusahakan.

\section{Payback Period (PP)}

Payback period (PP) adalah jangka waktu yang diperlukan untuk mengembalikan biaya investasi yang ditanamkan dalam periode hitungan tahun. Nilai Payback Period (PP) pada agroindustri keripik singkong Mbak Sur diperoleh dari nilai investasi dibagi dengan net benefit kemudian dikalikan dengan 1 Tahun. Dari hasil perhitungan hasil Payback Period pada usaha agroindustri keripik singkong Mbak Sur yaitu sebesar 0,75, yang artinya pengembalian investasi modal yang sudah ditanam akan kembali dalam waktu 0,06 Tahun atau 0,75 Bulan.

\section{Nilai Tambah}

Nilai tambah yaitu selisih antara harga jual produk dikurangi dengan jumlah biaya bahan baku dan biaya bahan penunjang. Berdasarkan perhitungan nilai tambah pada Lampiran 18 dapat dilihat bahwa harga jual produk adalah sebesar $\mathrm{Rp} 40.000$,-/kg sedangkan rata-rata biaya bahan baku sebesar $\mathrm{Rp}$ $1.500,-/ \mathrm{Kg}$, sehingga diperoleh nilai tambah pada usaha agroindustri keripik singkong Mbak Sur adalah sebesar Rp 37.371,-/ kg.

\section{KESIMPULAN}

1. Proses produksi keripik singkong pada Agroindustri Mbak Sur mulai dari pengupasan ubi kayu, pencucian, pengirisan, penggorengan, penirisan, pengadukan bumbu sampai pada pengemasan keripik ubi. Pemasaran hasil produksi dilakukan dengan cara menitipkan produk diwarung-warung yang

Diterbitkan oleh Program Studi Agribisnis Fakultas Pertanian Universitas Batanghari Jambi Halaman 41 
Jurnal Media Agribisnis Vol. 4 No. 1 Tahun 2019 Hal 34 - 42

Media Komunikasi Hasil Penelitian Bidang Ilmu Agribisnis

ISSN print 2548-7027

ISSN online 2541-6898

ada di wilayah Kecamatan Kumpeh dengan harga Rp 800,-/bungkus dan berat 20 gram per bungkus.

2. Pendapatan yang diterima pada agroindustri keripik singkong Mbak Sur sebesar Rp 8.451.560,-/bulan

- Nilai BEP produksi sebesar 9.245 bungkus/bulan jika dibandingkan dengan produksi pada agroindustri Mbak Sur yaitu sebanyak 19999 bungkus/bulan, sedangkan untuk BEP harga yaitu sebesar sebesar Rp 370,/bungkus,

- Nilai payback period (PP) adalah sebesar 0,75 bulan.

- Nilai tambah sebesar Rp 37.371,-/Kg

\section{DAFTAR PUSTAKA}

Bambang Riyanto, 2011. Dasar-Dasar Pembelanjaan Perusahaan, BBFE, Yogyakarta.

Dinas Perindustrian,Perdagangan dan Koperasi Kabupaten Muaro Jambi. 2014.

Hayami,1997.AgriculturalMarketing And Processing In Uplad

Mubyarto, 1995. Pengantar Ekonomi Pertanian. LP3ES. Jakarta.

Sarwono.B, 2007. Budidaya Singkong. Penebar Swadaya, Jakarta.

Syafri, 2002. Akuntansi Aktiva Tetap, Edisi Pertama, Penerbit PT. Raja Grafindo, Jakarta.

Soekartawi, 1995. Analisis Usahatani. Penerbit Universitas Indonesia (UI-Press), Jakarta. 